Table 2. Safety Profile: Number of participants (\%) experiencing any event

\begin{tabular}{|c|c|c|c|c|c|c|}
\hline & \multirow{2}{*}{$\begin{array}{l}\mathrm{PBO} \\
\mathrm{N}=33\end{array}$} & \multicolumn{4}{|c|}{ BIIB059 } & \multirow{2}{*}{$\frac{\text { OVERALL }}{\mathrm{N}=132}$} \\
\hline & & $50 \mathrm{mg} \mathrm{N}=26$ & $150 \mathrm{mg} \mathrm{N}=25$ & $450 \mathrm{mg} \mathrm{N}=48$ & Pooled $\mathrm{N}=99$ & \\
\hline Any Event, n(\%) & 18 (54.5) & $17(65.4)$ & $12(48)$ & $33(68.8)$ & $62(62.6)$ & $80(60.6)$ \\
\hline \multicolumn{7}{|l|}{ Severity } \\
\hline Mild & $11(33.3)$ & $11(42.3)$ & $8(32.0)$ & $19(39.6)$ & $38(38.4)$ & $49(37.1)$ \\
\hline Moderate & $4(12.1)$ & $6(23.1)$ & $3(12.0)$ & $12(25.0)$ & $21(21.2)$ & 25 (18.9) \\
\hline Severe & $3(9.1)$ & 0 & $1(4.0)$ & $2(4.2)$ & $3(3.0)$ & $6(4.5)$ \\
\hline Related events & $6(18.2)$ & $9(34.6)$ & $4(16.0)$ & $16(33.3)$ & $29(29.3)$ & $35(26.5)$ \\
\hline Serious events & $2(6.1)$ & 0 & $3(12.0)$ & $2(4.2)$ & $5(5.1)$ & $7(5.3)$ \\
\hline Related serious events & $1(3.0)$ & 0 & $1(4.0)$ & $1(2.1)$ & $2(2.0)$ & $3(2.3)$ \\
\hline Events leading to drug withdrawal & 0 & $1(3.8)$ & $1(4.0)$ & $1(2.1)$ & $3(3.0)$ & $3(2.3)$ \\
\hline Events leading to study withdrawal & 0 & 0 & 0 & $1(2.1)$ & $1(1.0)$ & $1(0.8)$ \\
\hline Fatal events & 0 & 0 & 0 & 0 & 0 & 0 \\
\hline
\end{tabular}

Alliance, Sanford Consortium, Consultant of: Genentech, Nektar, BMS, Janssen, AstraZeneca, Biogen, Vielabio, Equillium, Eli Lilly, ILTOO, Abbvie, Amgen, Roche, Gilead, Ronald van Vollenhoven Grant/research support from: AbbVie, Arthrogen, Bristol-Myers Squibb, GlaxoSmithKline, Lilly, Pfizer, and UCB, Consultant of: AbbVie, AstraZeneca, Biotest, Bristol-Myers Squibb, Celgene, GSK, Janssen, Lilly, Medac, Merck, Novartis, Pfizer, Roche, and UCB, Filippa Nyberg Consultant of: Biogen, Benjamin Kaffenberger Grant/research support from: Amgen, Biogen, InflaRx, Veloce Biopharmaceuticals, Dermatology Foundation, Saira Sheikh: None declared, Goran Radunovic: None declared, XIAOBI HUANG Shareholder of: Biogen, Employee of: Biogen, HUA CARROLL Shareholder of: Biogen, Employee of: Biogen, Francois Gaudreault Shareholder of: Biogen, Employee of: Biogen, Adam Meyers Shareholder of: Biogen, Employee of: Biogen, Catherine Barbey Shareholder of: Biogen, Employee of: Biogen, Cristina Musselli Shareholder of: Biogen, Employee of: Biogen, NATHALIE FRANCHIMONT Shareholder of: Biogen, Employee of: Biogen

DOI: 10.1136/annrheumdis-2020-eular.5743

\section{OP0194 IMMUNOSUPPRESSIVE EFFECT OF TOLEROGENIC DENDRITIC CELLS ON AUTOLOGOUS T-CELLS IN PATIENTS WITH RHEUMATOID ARTHRITIS}

Y. Kurochkina ${ }^{1}$, T. Tyrinova ${ }^{2}$, O. Leplina ${ }^{2}$, M. Tikhonova ${ }^{2}$, A. Sizikov $^{2}$, O. Chumasova ${ }^{2}$, A. Ostanin ${ }^{2}$, E. Chernykh ${ }^{2}{ }^{1}$ Research Institute of Clinical and Experimental Lymphology - Branch of the Institute of Cytology and Genetics, Siberian Branch of the Russian Academy of Science, Novosibirsk, Russian Federation; ${ }^{2}$ Federal State Budgetary Scientific Institution Research Institute of Fundamental and Clinical Immunology, Novosibirsk, Russian Federation

Background: Dendritic cells (DCs) are known to contribute to the pathogenesis of rheumatoid arthritis (RA) through presentation of cartilage glycoprotein, production of proinflammatory cytokines and activation of Th1/Th17 responses. Along with stimulating activity, DCs may exhibit suppressive functions via capacity to induce $\mathrm{T}$ cell apoptosis/anergy and to generate regulatory $\mathrm{T}$ cells. Since these DCs have potential to control autoreactive T-lymphocytes, the enhancing of tolerogenic properties of DCs seems to be a new important strategy in treatment of RA. However, it remains unclear whether autoreactive T lymphocytes are sensitive to the immunosuppressive effects of DC.

Objectives: The aim of our study is to investigate the mechanisms of the inhibitory effect of dexamethasone-modified DCs (dexDCs) in patients with RA on autologous $T$ cells.

Methods: Twenty patients with RA with high and moderate activity of disease were recruited in this study. All patients fullfield ACR/EULAR criteria (2010). All studies were performed after receiving informed consent. DCs were generated from blood monocytes culturing for 5 days with GM-CSF and IFN-a in the presence dexamethasone, applied on third day. LPS as maturation stimuli was added on fourth day. The study evaluated the ability of dexDCs to induce T cell apoptosis, inhibit the production of Th1 and Th17 cytokines in auto-mixed leukocytes culture (MLC), induce the activation of T-regulatory cells, and inhibit the purified protein derivative (PPD)-specific immune response.

Results: We revealed that dexDCs markedly suppressed the production of IFN- $\gamma$ and IL-17, while the decreasing of IL-4 and IL-13 was less pronounced. Thus, in comparison with Th2 cells, Th1 and Th17 T lymphocytes were more sensitive to suppressor effects of dexDCs. We also revealed a significant increasing of cells in the stage of late apoptosis $(\mathrm{An}+\mathrm{Pi}+)$ during the cultivation of autologous $\mathrm{T}$ cells with dexDCs. We have also proved the suppressive effect of dexDCs on culture $T$ cells that are co-cultivated with mature DCs (reduction of proliferation from 2700 cpm to $1500 \mathrm{cpm}, \mathrm{p}=0.0015)$. In addition, we have shown the ability of dexDCs to induce T-regulatory cells with a phenotype CD4+IL10+Tr1. In conclusion, we have shown the ability of PPD-loaded dexDCs to inhibit the proliferative response of both mature DCS and mature dexDCs-loaded PPD, that indicates the ability of dexDCs to possess antigen-specific suppression.

Conclusion: The data obtained indicate that, dexDCs from RA patients have an immunosuppressive effect on autologous $T$ cells through the induction of apoptosis, anergia and activation of $T$ regulatory cells that authorise their application as a DCs-vaccine.

Disclosure of Interests: None declared

DOI: 10.1136/annrheumdis-2020-eular.1291

\section{Creating in vitro patients - how to best model disease}

\section{OP0195 VASCULARIZED THREE-DIMENSIONAL MODELS OF HUMAN SKIN FIBROSIS}

A. E. Matei ${ }^{1}$, C. W. Chen ${ }^{1}$, L. Kiesewetter ${ }^{2}$, A. H. Györfi' ${ }^{1}$, Y. N. LI ${ }^{1}$, T. TrinhMinh $^{1}$, T. Van Kuppevelt ${ }^{3}$, J. Hansmann ${ }^{2,4}$, A. Juengel ${ }^{5}$, G. Schett ${ }^{1}$, F. GroeberBecker $^{2,6}$, J. Distler ${ }^{1} .{ }^{1}$ Department of Internal Medicine 3 - Rheumatology and Immunology, Friedrich-Alexander-University Erlangen-Nürnberg (FAU) and University Hospital Erlangen, Erlangen, Germany; ${ }^{2}$ Translational Center Würzburg, Fraunhofer Translational Center Regenerative Therapies, Fraunhofer Institute for Silicate Research (ISC), Würzburg, Germany; ${ }^{3}$ Radboud Institute for Molecular Life Sciences, Department of Biochemistry, Radboud University Medical Center, Nijmegen, Netherlands; ${ }^{4}$ University for Applied Sciences Würzburg-Schweinfurt, Würzburg, Germany; ${ }^{5}$ Center of Experimental Rheumatology, University Hospital Zurich/Zurich Center of Integrative Human Physiology (ZIHP), Zürich, Switzerland; ${ }^{6}$ Department for Tissue Engineering and Regenerative Medicine, Würzburg University Medical Center, Würzburg, Germany

Background: The complex pathophysiological processes that result in fibrotic tissue remodeling in systemic sclerosis involve interplay between multiple cell types (1). Experimental models of fibrosis are essential to provide a conceptual understanding of the pathogenesis of these diseases and to test antifibrotic drugs. Current models of fibrosis have important limitations: the in vivo models rely on species that are phylogenetically distant, whereas the in vitro models are oversimplified cultures of a single cell type in an artificial two-dimensional environment of excessive stiffness, which imposes an unphysiological cell polarization (2).

Objectives: Here we evaluated the potential use of vascularized, three-dimensional in vitro human skin equivalents as a novel model of skin fibrosis and a platform for the evaluation of antifibrotic drugs.

Methods: Skin equivalents were generated by seeding human endothelial cells, fibroblasts and keratinocytes on a decellularized porcine extracellular matrix with perfusable vascular structure. The skin models were cultured for one month in a system that ensured perfusion of the vascular network at physiological pressure. Fibrotic transformation induced by TGF $\beta$ and response to nintedanib as an established antifibrotic drug was evaluated by capillary Western immunoassays, qPCR, histology and immunostaining.

Results: The vascularized human skin equivalents formed the major skin structures relevant for the pathogenesis of fibrosis: a polarized, fully matured epidermis, a stratified dermis and a perfused vessel system with small capillaries. Exposure to TGF $\beta$ led to the fibrotic transformation of the skin equivalents, with activated TGF $\beta$ downstream pathways, increased fibroblast-to-myofibroblast transition and excessive deposition of extracellular matrix. Treatment of models exposed to TGF $\beta$ with nintedanib (a drug with proven antifibrotic effects) ameliorated the fibrotic transformation of skin equivalents with reduced TGF $\beta$ signaling, fibroblast-to-myofibroblast transition and decreased extracellular matrix deposition. 
Conclusion: Here we describe a novel in vitro model of skin fibrosis. Our data show that vascularized skin equivalents can reproduce all skin layers affected by fibrosis, that, upon exposure to TGF $\beta$, these models recapitulate key features of fibrotic skin and that these skin models can be used as a platform for evaluation of antifibrotic drugs in a setting with high relevance for human disease.

References:

[1] Distler JHW, Gyorfi AH, Ramanujam M, Whitfield ML, Konigshoff M, Lafyatis R. Shared and distinct mechanisms of fibrosis. Nature reviews Rheumatology. 2019;15(12):705-30.

[2] Garrett SM, Baker Frost D, Feghali-Bostwick C. The mighty fibroblast and its utility in scleroderma research. Journal of scleroderma and related disorders. 2017;2(2):69-134.

Disclosure of Interests: Alexandru-Emil Matei: None declared, Chih-Wei Chen: None declared, Lisa Kiesewetter: None declared, Andrea-Hermina Györfi: None declared, Yi-Nan Li: None declared, Thuong Trinh-Minh: None declared, Toin van Kuppevelt: None declared, Jan Hansmann: None declared, Astrid Juengel: None declared, Georg Schett Speakers bureau: AbbVie, BMS, Celgene, Janssen, Eli Lilly, Novartis, Roche and UCB, Florian Groeber-Becker: None declared, Jörg Distler Grant/research support from: Boehringer Ingelheim, Consultant of: Boehringer Ingelheim, Paid instructor for: Boehringer Ingelheim, Speakers bureau: Boehringer Ingelheim

DOI: 10.1136/annrheumdis-2020-eular.3141

\section{Time2Work - why and how to act}

\section{OP0196-PARE \#ARTHRITISATWORK: USING TWITTER TO ENGAGE THE INTERNATIONAL ARTHRITIS COMMUNITY}

L. Proulx ${ }^{1}$, S. Stones ${ }^{2}$, J. Coe ${ }^{3}$, D. Richards ${ }^{1}$, L. Wilhelm ${ }^{1}$, N. Robertson ${ }^{1}$, J. Gunderson ${ }^{1}$, A. Sirois ${ }^{1}$, A. Mckinnon ${ }^{1} .{ }^{1}$ Canadian Arthritis Patient Allianc, Ottawa, Canada; ${ }^{2}$ Collaboro Consulting, Bolton, United Kingdom; ${ }^{3}$ Creaky Joints, New York, United States of America

Background: In 2019, EULAR launched the \#Time2Work campaign [1] to raise awareness of the impact of rheumatic and musculoskeletal diseases on individuals, society, and the economy. Building on this theme, the Canadian Arthritis Patient Alliance (CAPA) developed a social media campaign and Twitter chat in collaboration with international patient advocates and organizations. The Twitter chat built upon CAPA's successful development of workplace resources for people living with arthritis [2]

Objectives: To deliver an international \#ArthritisAtWork social media campaign on Twitter, in support of the \#Time2Work campaign.

Methods: A one-hour Twitter Chat was held on World Arthritis Day (October 12 2019) on arthritis in the workplace (\#ArthritisAtWork) from 18:00 to 19:00 UTC. The chat was hosted by CAPA and co-hosted by Simon Stones, a patient advocate from the United Kingdom (UK) and CreakyJoints, patient-driven arthritis organization in the United States (US). The Twitter Chat questions were co-developed in advance by the hosts, and blog posts were shared from CAPA's website. Each host also promoted the Twitter Chat through their websites newsletters and online communities. A social media analytical tool, Symplur was used to measure audience engagement using the hashtag \#ArthritisAtWork. In addition, pertinent Tweets before, during, and after the chat were obtained. The analysis of themes was undertaken to identify common issues and questions.

Results: One hundred and ten users participated in the Twitter chat between 17:20 and 19:20 UTC. Participants included people living with arthritis, researchers, patient organizations, health information outlets and academic institutions. During this period, 565 tweets were shared between participants in Australia, Canada, Ireland, Spain, UK and US. There were 3.352 million Twitter impressions. This represents the number of times a tweet appears to users in either their timeline or search results. Emergent themes of the analysis include:

- common workplace challenges such as employer attitudes and stigma;

- effective workplace supports such as prioritizing tasks and requesting workplace accommodations; and

- areas of improvement such as instituting workplace policies, flexible workplace approaches and education for employees and managers.

Conclusion: The social media campaign was successful in reaching a diverse audience and supporting the \#Time2Work campaign. Social media tools can provide an important social support for people living with arthritis as they navigate workplace challenges. It also offers a more contemporary platform to engage the international community on issues of common interest. Working together, internationally helps expand reach and reduce barriers in communication. Research can be conducted to measure potential behavior change that leverages digital social support for people living with arthritis.

\section{References:}

[1] EULAR (2019). Press release "EULAR launches Time2Work campaign to highlight the importance of keeping people with rheumatic and musculoskeletal diseases in work. Available from: https://www.eular.org/sysModules/obxContent/files/www.eular.2015/1_42291DEB-50E5-49AE-5726D0FAAA83A7D4/ time2work_campaign_press_release_final.pdf 2.CAPA (2019).Arthritis in the Workplace: Resources for Patients by Patients. Available from: http://arthritispatient.ca/arthritis-in-the-workplace-resources-for-patients-by-patients/

Disclosure of Interests: Laurie Proulx Grant/research support from: Sources of grants and support received by the Canadian Arthritis Patien Alliance (including in-kind support) in the last two years include: AbbVie Canada, Alliance for Safe Biologic Medicines, Amgen Canada, Arthritis Alliance of Canada, The Arthritis Society, Best Medicines Coalition, CADTH, Canadian Rheumatology Association, Eli Lilly Canada, European League Against Rheumatism, Janssen Canada, Manulife, Novartis Canada, Ontario Rheumatology Association, Pfizer Canada (including Pfizer Hospira), Purdue Pharma Canada, Sanofi, and UCB Pharma., Speakers bureau: I have provided speaking services to Sanofi and Eli Lilly. These engagements do not relate to this abstract., Simon Stones Consultant of: I have been a paid consultant for Envision Pharma Group and Parexel. This does not relate to this abstract., Speakers bureau: I have been a paid speaker for Actelion and Janssen. These do not relate to this abstract., Joseph Coe: None declared, Dawn Richards Grant/research support from: Sources of grants and support received by the Canadian Arthritis Patient Alliance (including in-kind support) in the last two years include: AbbVie Canada, Alliance for Safe Biologic Medicines, Amgen Canada, Arthritis Alliance of Canada, The Arthritis Society, Best Medicines Coalition, CADTH, Canadian Rheumatology Association, Eli Lilly Canada, European League Against Rheumatism, Janssen Canada, Manulife, Novartis Canada, Ontario Rheumatology Association, Pfizer Canada (including Pfizer Hospira), Purdue Pharma Canada, Sanofi, and UCB Pharma., Consultant of: Dawn has done small consulting projects on patient engagement for companies., Speakers bureau: Dawn has been a paid speaker for several companies., Linda Wilhelm Grant/research support from: Sources of grants and support received by the Canadian Arthritis Patient Alliance (including in-kind support) in the last two years include: AbbVie Canada, Alliance for Safe Biologic Medicines, Amgen Canada, Arthritis Alliance of Canada, The Arthritis Society, Best Medicines Coalition, CADTH Canadian Rheumatology Association, Eli Lilly Canada, European League Against Rheumatism, Janssen Canada, Manulife, Novartis Canada, Ontario Rheumatology Association, Pfizer Canada (including Pfizer Hospira), Purdue Pharma Canada, Sanofi, and UCB Pharma., Nathalie Robertson Grant/ research support from: Sources of grants and support received by the Canadian Arthritis Patient Alliance (including in-kind support) in the last two years include: AbbVie Canada, Alliance for Safe Biologic Medicines, Amgen Canada, Arthritis Alliance of Canada, The Arthritis Society, Best Medicines Coalition, CADTH, Canadian Rheumatology Association, Eli Lilly Canada European League Against Rheumatism, Janssen Canada, Manulife, Novartis Canada, Ontario Rheumatology Association, Pfizer Canada (including Pfizer Hospira), Purdue Pharma Canada, Sanofi, and UCB Pharma., Janet Gunderson Grant/research support from: Sources of grants and support received by the Canadian Arthritis Patient Alliance (including in-kind support) in the last two years include: AbbVie Canada, Alliance for Safe Biologic Medicines, Amgen Canada, Arthritis Alliance of Canada, The Arthritis Society, Best Medicines Coalition, CADTH, Canadian Rheumatology Association Eli Lilly Canada, European League Against Rheumatism, Janssen Canada, Manulife, Novartis Canada, Ontario Rheumatology Association, Pfizer Canada (including Pfizer Hospira), Purdue Pharma Canada, Sanofi, and UCB Pharma., Alexandra Sirois Grant/research support from: Sources of grants and support received by the Canadian Arthritis Patient Alliance (including in-kind support) in the last two years include: AbbVie Canada, Alliance for Safe Biologic Medicines, Amgen Canada, Arthritis Alliance of Canada, The Arthritis Society, Best Medicines Coalition, CADTH, Canadian Rheumatology Association, Eli Lilly Canada, European League Against Rheumatism Janssen Canada, Manulife, Novartis Canada, Ontario Rheumatology Association, Pfizer Canada (including Pfizer Hospira), Purdue Pharma Canada Sanofi, and UCB Pharma., Annette McKinnon Grant/research support from: Sources of grants and support received by the Canadian Arthritis Patient Alliance (including in-kind support) in the last two years include: AbbVie Canada, Alliance for Safe Biologic Medicines, Amgen Canada, Arthritis Alliance of Canada, The Arthritis Society, Best Medicines Coalition, CADTH Canadian Rheumatology Association, Eli Lilly Canada, European League Against Rheumatism, Janssen Canada, Manulife, Novartis Canada, Ontario Rheumatology Association, Pfizer Canada (including Pfizer Hospira), Purdue Pharma Canada, Sanofi, and UCB Pharma. DOI: 10.1136/annrheumdis-2020-eular.4793 